Original

\title{
Effect of demineralization time on the mineral composition and mechanical properties of remineralized dentin
}

\author{
Olivier Lavigne'), Anh M. Vu²), Lindsay Richards'2), and Zonghan Xie') \\ 1)School of Mechanical Engineering, The University of Adelaide, Adelaide, SA, Australia \\ 2)School of Dentistry, The University of Adelaide, Adelaide, SA, Australia
}

(Received January 24, 2017; Accepted May 1, 2017)

\begin{abstract}
The aim of this study was to determine whether recovery of mineral levels restored the mechanical properties of dentin subjected to different durations of demineralization. Dentin at the floor of class 1 cavities $(n=12)$ was demineralized for 1,2 , and 3 weeks. Half the demineralized cavity floor was coated (control side), and a Fuji IX restoration was placed. The remaining half was therefore in contact with the Fuji IX restoration (test side). Simulated dentin tubular fluid was then supplied to each pulp chamber for 6 weeks. After remineralization, the teeth were detached from the system and sectioned. Concentrations of calcium, phosphorus, fluorine, and strontium and mechanical properties (hardness and Young's modulus) of the test and control sides were determined by electron probe microanalysis and nano-indentation, respectively. For remineralized dentin demineralized for 1 week, the substantial uptake of mineral elements restored hardness and Young's modulus at depths of 50 to $200 \mu \mathrm{m}$ from the lesion front. For longer periods of demineralization ( 2 and 3 weeks), structural damage to the demineralized dentin was severe and impeded recovery of mechanical properties, despite mineral uptake.
\end{abstract}

Keywords: caries; mechanical properties; mineral content; remineralization; tooth dentin.

Correspondence to Dr. Olivier Lavigne, School of Mechanical Engineering, The University of Adelaide, Adelaide, SA 5005, Australia

Fax:+61-8-8313-4367 E-mail: olivier.lavigne@adelaide.edu.au

Color figures can be viewed in the online issue at J-STAGE.

doi.org/10.2334/josnusd.17-0038

DN/JST.JSTAGE/josnusd/17-0038

\section{Introduction}

Tooth caries has been studied for many decades, and the underlying process is now well understood. Caries formation is a dynamic process and results from demineralization and remineralization of enamel and dentin. When the balance of this dynamic process tips towards remineralization, the caries process is reversed and the demineralized enamel/dentin is remineralized (1-3). When the balance tips towards demineralization, the minerals contained in the enamel/dentin dissolve and the dentin matrix is eventually destroyed (4), and the mechanical properties of affected tissues are substantially degraded $(4,5)$. The disease is reversible, however, if detected early enough (6).

Carious dentin exhibits gradual depletion of minerals at depth, and bacterial penetration is variable and sometimes quite deep $(2,3,7)$. Bacteria-infiltrated dentin can be sealed by a restoration, which halts the disease process (7). Restoration by means of indirect pulp capping technique and atraumatic restorative treatment are based on the removal of irreparably damaged dentin down to a "firm" surface, to be remineralized before placement of a glass-ionomer cement (GIC) restoration (Frencken JE, Holmgren CJ. Atraumatic restorative treatment for dental caries, STI book bv, 1999). A number of studies (7-9) reported that GIC exhibits a chemical adhesion mechanism and a remineralization effect. Outcomes of dentin remineralization are usually assessed by quantitative analysis of the mineral content of remineralized structures or by measuring the mechanical properties of dentin (10). Assessment of mechanical properties of remineralized dentin is particularly useful, as it is hypothesized that recovery of mechanical properties improves when 
minerals are effectively re-associated with the organic matrix, and that recovery of mechanical properties is limited when minerals are regained but poorly attached to the matrix $(4,10)$. Some studies have reported a correlation between the mechanical properties and mineral content of dentin $(4,5,10$, Dalidjan M. Caries inhibitory effect of fluoride co-crystallized sucrose: establishing a field trial, PhD Thesis, University of Adelaide, 1995). However, information on the mechanical properties (hardness, H, and Young's modulus, E) of demineralized dentin remineralized in the presence of simulated dentin tubular fluid (SDTF) and GIC is anecdotal and limited. Moreover, demineralization time is an important factor, as caries can be treated and reversed if detected early enough. The aims of this study were thus to analyze the effect of demineralization time on the mineral content and mechanical properties of dentin remineralized in the presence of SDTF and a Fuji IX restoration and to develop a laboratory-based model that simulates in vivo conditions.

\section{Materials and Methods \\ Teeth collection and selection}

Intact third molars were collected after receiving approval from the Adelaide University Human Ethics Committee. We chose to use previously unerupted teeth, to ensure that dentin tubules remained patent. The selected teeth had closed apexes and a pulp chamber height of around 2 $\mathrm{mm}$. The closure of the apexes, which occurs at about age 18 to 22 years $(11,12)$, and the size of the pulp chamber reflected the maturation of the selected teeth. Narrower pulp chambers are associated with older teeth with lower permeability, and wider pulp chambers are associated with younger teeth that can be too permeable (13). Using the presented selection criteria, we expected the selected teeth to have similar dentin permeability characteristics.

The teeth were cleaned to remove the remaining soft and hard tissues and stored in a $0.2 \%$ thymol $\left(\mathrm{C}_{10} \mathrm{H}_{14} \mathrm{O}\right)$ solution in a refrigerator at $4{ }^{\circ} \mathrm{C}$ until they were used.

\section{Sample preparation}

Occlusal Class 1 cavities (dimensions: $5 \mathrm{~mm}$ mesiodistally, $4 \mathrm{~mm}$ buccolingually, occlusal depth, $3 \mathrm{~mm}$ ) ending in dentin were prepared by using high-speed handpieces with water-cooled diamond burs (Friction Grip Cylinder 541-Coarse Grit [6070454], head diameter $1 \mathrm{~mm}$, head length $3 \mathrm{~mm}$ ). Care was taken to ensure that dentin was not dehydrated during cavity preparation. A bench stereomicroscope (Leitz, Wetzlar, Germany) was used to check the floor of the cavities to ensure that no enamel remained and that no irregularities were present. The teeth and cavity walls were then coated with a protective nail varnish. The cavity floors (dentin) were left exposed to demineralization to create a dentin surface similar to that found after carious attack (7). The demineralizing solution contained $2.2 \mathrm{mmol}$ of dicalcium phosphate $\left(\mathrm{CaHPO}_{4}\right)$ and $2.85 \mathrm{~mL} / \mathrm{L}$ of concentrated glacial acetic acid adjusted to $\mathrm{pH} 4.3$ with $10 \%$ of sodium hydroxide $(\mathrm{NaOH})(\mathrm{Vu}$ Thanh AM. An enhanced in vitro model to study the effectiveness of dentinal fluid on remineralization, $\mathrm{PhD}$ Thesis, University of Adelaide, 2008). The teeth were divided into three groups (of four teeth each), and each group was exposed to 1, 2, or 3 weeks of demineralization. The crowns were then sectioned horizontally at a point 2-mm apical to the cemento-enamel junction, to remove the root with an IsoMet slow-speed sectioning machine (Buehler, Lake Bluff, IL, USA) equipped with a Diamond Watering Blade (Van Moppes, Geneva, Switzerland). A slot was cut in the middle of the cavity with a half-round bur that divided the cavity into two equal halves. Before placing the restoration, half the demineralized cavity floor was painted with nail varnish, to create a control side, while the other half remained unpainted (test side). This allowed for contact between demineralized dentin and the restoration on the test side and enabled ion exchange between the restoration and demineralized dentin. Fuji IX (GC Corporation, Tokyo, Japan) was selected in this study as the restorative material to seal the cavity. Fuji IX contains strontium and fluorine but no calcium (and no phosphorus), which allowed us to follow calcium movement from the SDTF into the demineralized dentin without the complication of calcium diffusing from the restorative material. To simulate atraumatic restorative treatment more closely, the powder/liquid manual mix version of Fuji IX was used. Just before placing the restorative material, the test half of the cavity was conditioned for $10 \mathrm{~s}$ with $10 \%$ polyacrylic acid (Dentin Conditioner, GC Corporation). The cavity was then washed for $20 \mathrm{~s}$ and dried for 5 to 10 $\mathrm{s}$ but not desiccated. Fuji IX was then mixed and placed into the cavity, and the crowns were stored in a humidor for 1 hour to permit initial setting of the GIC. To simulate the natural hydrostatic pressure of $1.47 \mathrm{kPa}$ in the pulp chamber, an SDTF reservoir was connected and placed $15 \mathrm{~cm}$ above the teeth (14). The SDTF formula selected contained $7.149 \mathrm{~g} / \mathrm{L}$ HEPES $\left(\mathrm{C}_{8} \mathrm{H}_{18} \mathrm{~N}_{2} \mathrm{O}_{4} \mathrm{~S}\right), 1.1 \mathrm{~mL} / \mathrm{L}$ of $1 \mathrm{M}$ phosphoric acid $\left(\mathrm{H}_{3} \mathrm{PO}_{4}\right), 0.123 \mathrm{~g} / \mathrm{L}$ of calcium oxide $(\mathrm{CaO})$ or $0.163 \mathrm{~g} / \mathrm{L}$ of calcium hydroxide $\left(\mathrm{Ca}(\mathrm{OH})_{2}\right)$, $1.54 \mathrm{~g} / \mathrm{L}$ of sodium chloride $(\mathrm{NaCl})$, and $1 \mathrm{~g} / \mathrm{L}$ thymol with the $\mathrm{pH}$ adjusted to 7 (14-16). The calcium level in the SDTF was $2.2 \mathrm{mmol} / \mathrm{L}$. The duration of the remineralization process in the presence of Fuji IX and SDTF 


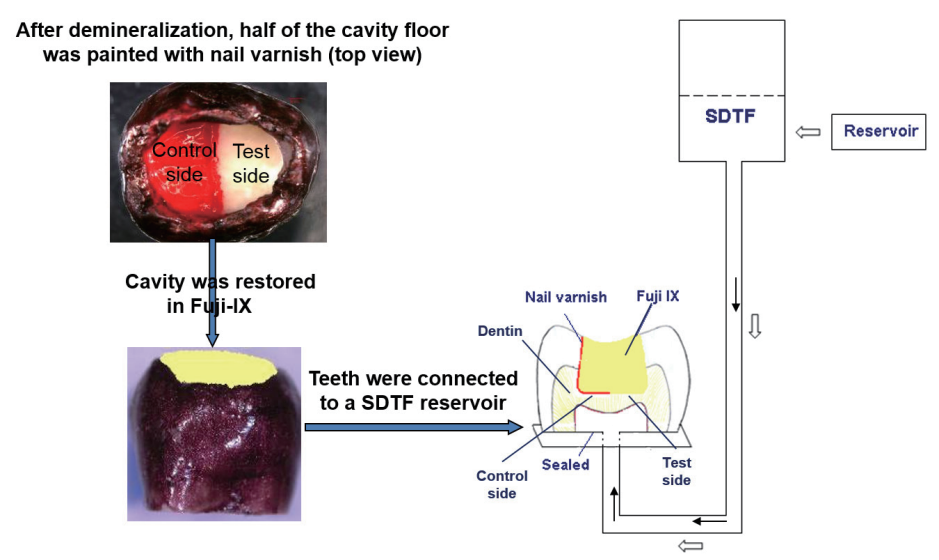

Fig. 1 Experimental design for model of dentin remineralization in the presence of SDTF and a Fuji IX restoration (Vu Thanh AM. An enhanced in vitro model to study the effectiveness of dentinal fluid on remineralization, $\mathrm{PhD}$ Thesis, University of Adelaide, 2008).

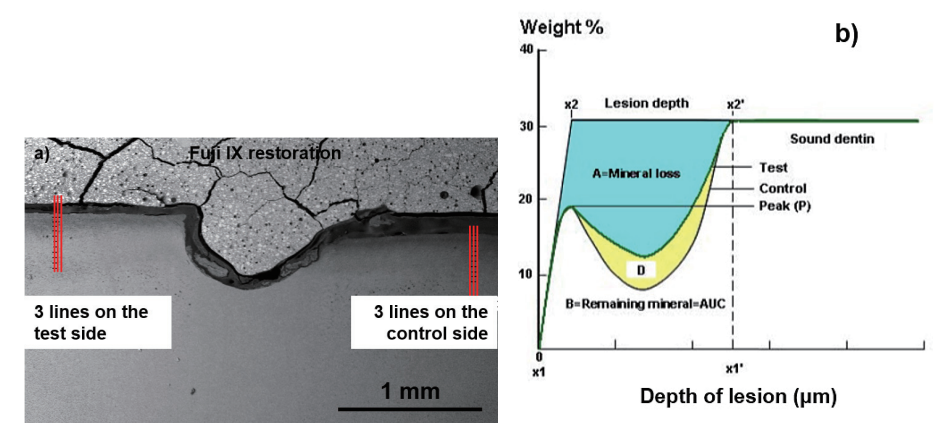

Fig. 2 a) Electron probe microanalysis was used to determine elemental profiles across dentin on the test and control sides of samples, b) Quantification of mineral element loss/gain on electron probe microanalysis.

was 6 weeks. The demineralization and remineralization experimental steps were conducted at $37^{\circ} \mathrm{C}$. A schematic of the sample preparation is shown in Fig. 1, and sample group preparation is summarized in Table 1. After remineralization, the crowns were detached from the system, sectioned into two halves, and dehydrated by using progressively higher concentrations of ethanol solutions (Vu Thanh AM. An enhanced in vitro model to study the effectiveness of dentinal fluid on remineralization, $\mathrm{PhD}$ Thesis, University of Adelaide, 2008), to minimize dentin shrinkage (7). Dentin dehydration was necessary because water contamination may result in inaccurate results for electron probe microanalysis (EPMA). Finally, the specimens were embedded in epoxy resin and polished up to a final polishing step by using a diamond-powder suspension $(1 \mu \mathrm{m})$.

\section{Electron probe microanalysis}

Samples were carbon-coated (thickness $20 \mathrm{~nm}$ ) with a Denton DV502 Vacuum chamber, to ensure electrical conductivity of the surfaces. A Cameca SX51 Electron
Microprobe was used at a voltage of $15 \mathrm{kV}$ and a current beam of $20 \mathrm{~mA}$. Counting time was $10 \mathrm{~s}$ on the peak and 5 $\mathrm{s}$ on each of the backgrounds for both the standard known composition (during calibration) and restorative materials/dentin (during analysis). Wavelength-dispersive spectroscopy was used with SAMx software performed with the iDFIX program. The analysis was carried out across the samples' surfaces to determine the concentration profiles of calcium $(\mathrm{Ca})$, phosphorus $(\mathrm{P})$, strontium $(\mathrm{Sr})$, and fluorine (F) (in relative weight \%). Three lines on both the test and control sides of the lesion were analyzed (Fig. 2a), and the results were averaged for each depth. Each line comprised 101 points, and the interval between points was $5 \mu \mathrm{m}$. Under certain circumstances, the analysis was made at a point $100 \mu \mathrm{m}$ within the restoration, to search for migrated elements. The calibration was done by comparing the peak and background intensity with Astimex $13\left(\mathrm{SrSO}_{4}\right)$, Fluorite, and Cameca Apatite Standard $\left(\mathrm{CaPO}_{4}\right)$.

To quantify the effects of remineralization on dentin, the elemental concentration $v s$. depth curves measured 
Table 1 Experimental design

\begin{tabular}{llcl}
\hline \multirow{2}{*}{ Sample group } & \multicolumn{2}{c}{ Dentin conditioning } & Control side \\
\cline { 2 - 4 } 1 & 1 week of demineralization followed by 6 weeks of remineralization & 1 week of demineralization \\
2 & 2 weeks of demineralization followed by 6 weeks of remineralization & 2 weeks of demineralization \\
3 & 3 weeks of demineralization followed by 6 weeks of remineralization & 3 weeks of demineralization \\
\hline
\end{tabular}

Each sample group comprised four samples of both the test and control sides.
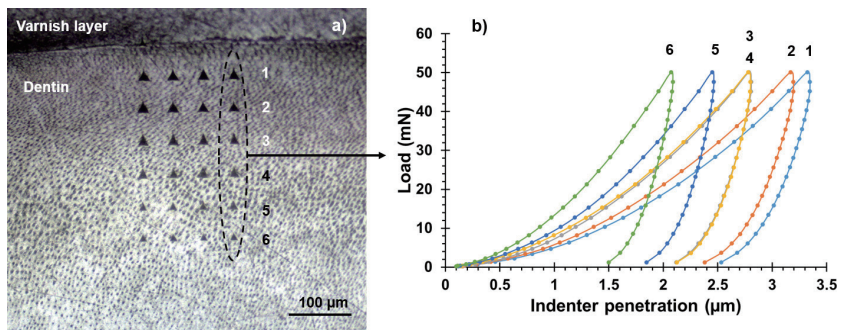

Fig. 3 a) Array of $4 \times 6$ indents at a 50-mN load, b) Example of corresponding load $v s$. depth curves: a decrease in indenter penetration depth (smaller indent size) with distance from the lesion front indicates an increase in dentin hardness.

by EPMA were analyzed, as indicated in Fig. 2b. The area under the curve (B) of each element represents the remaining value of that element, while the area above that curve (A) represents the loss of that element. The difference (D) between the areas under the curve of the test side and control side indicates the difference in mineral element level and enables comparison of mineral loss or gain between the test and control sides. The areas under the curves were calculated to depth $\mathrm{x} 1^{\prime}$ ' (Fig. 2b) of $350 \mu \mathrm{m}$.

To determine whether differences between the means in elemental concentrations of the test and control sides were statistically significant, $P$ values were obtained with one-way analysis of variance (ANOVA) and compared to a selected significance level, $\alpha$, of 0.05 : an $\alpha$ of 0.05 indicates a $5 \%$ risk of concluding that a difference exists when no actual difference is present. A $P$ value of 0.05 or less was considered to indicate statistical significance.

\section{Analysis of mechanical characteristics}

An IBIS nano-indentation system (Fischer-Cripps Laboratories Pty Ltd., Sydney, Australia) equipped with a Berkovich indenter was used to measure the distribution of the near-surface mechanical properties of the samples. The contact area of the tip as a function of the penetration depth was first calibrated on fused silica (17). Arrays of $4 \times 6$ indents with $50-\mu \mathrm{m}$ spacing were made on the four different samples of each group on both the test and control sides (Table 1). Measurements were started from $50 \mu \mathrm{m}$ below the lesion front (Fig. 3). The properties reported at a given distance from the lesion front were the average of the values resulting from the four indents in a given row for each of the four samples of each group (thus, the average number of indents per depth for each sample group was 16). This method minimizes variation in measured properties resulting from differences in the local microstructure at the indentation sites (18). The tests were run under controlled load conditions. A maximum load of $50 \mathrm{mN}$ was applied (19-22) in 20 increments, followed by unloading in 20 decrements. Using the Oliver-Pharr method, we calculated hardness, H, and Young's modulus, E, from the recorded load vs. depth curves (Fig. 3b) (17).

\section{Results}

Analysis of mineral element concentration profile

Figure 4 shows the mineral element profile for $\mathrm{Ca}, \mathrm{P}, \mathrm{F}$, and $\mathrm{Sr}$ for sample group 1 (Fig. 4a-d), sample group 2 (Fig. 4e-h), and sample group 3 (Fig. 4i-1). The lesion front is located at $0 \mu \mathrm{m}$ depth. Longer demineralization time was associated with increased mineral loss in deep dentin. Indeed, sound dentin, which contains about 30\% $\mathrm{Ca}$ (7), was present at depths of approximately 250,300 , and $450 \mu \mathrm{m}$ in sample group 1 (Fig. 4b), sample group 2 (Fig. 4h), and sample group 3 (Fig. 4l), respectively. In most samples, the $\mathrm{Ca}$ and $\mathrm{P}$ profiles on the control side of samples exhibited the classical carious lesion characteristic of a mineral element concentration peak at the lesion front followed by a drop in mineral concentration between depths of 250 and $400 \mu \mathrm{m}$, the extent of which depended on demineralization time (Fig. 4b, d, h, 1). Lesion severity was moderate to advanced according to the American 


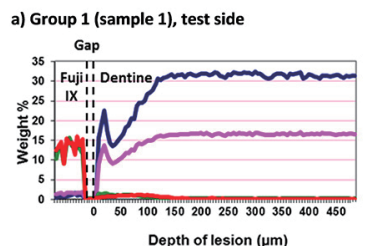

Depth of lesion $(\mu \mathrm{m})$
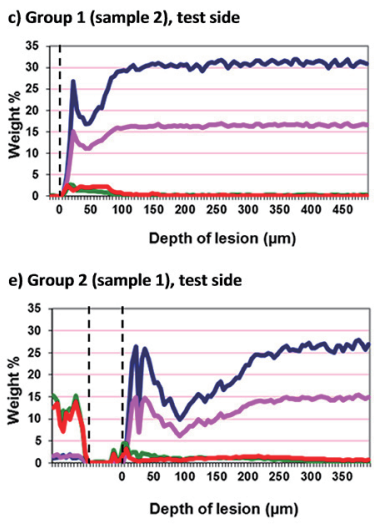

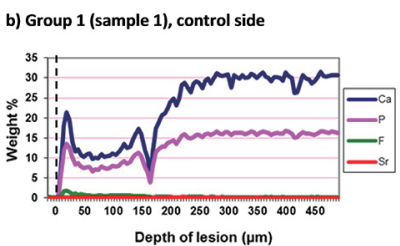

Depth of lesion ( $\mu \mathrm{m})$
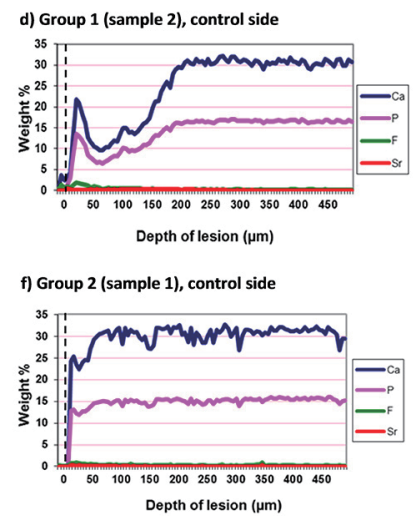

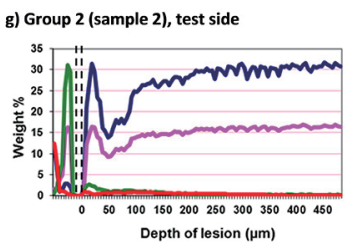

Depth of lesion $(\mu \mathrm{m})$
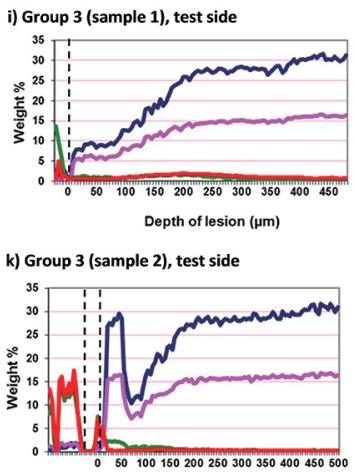

Depth of lesion ( $\mu \mathrm{m})$
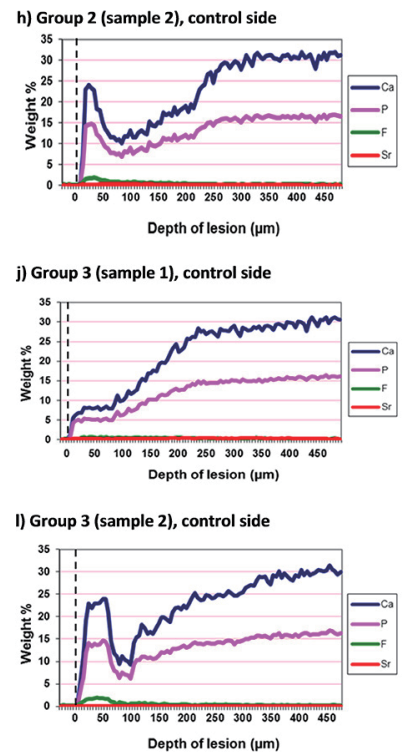

Fig. $4 \mathrm{Ca}, \mathrm{P}, \mathrm{F}$, and $\mathrm{Sr}$ profiles (by wt \%) measured by electron probe microanalysis across dentin on the test and control sides for a-d) two samples from group 1; e-h) two samples from group 2; and i-1) two samples from group 3. The outer surface of the dentin (or lesion front) is located at depth $0 \mu \mathrm{m}$ on the $\mathrm{x}$-axis of the graphs.

Dental Association dental caries classification system (Iannuci JM, Howerton LJ. Dental radiography, Elsevier Saunders, 2012). The trend was similar on the test side of the samples; however, amounts of $\mathrm{Ca}$ and $\mathrm{P}$ were higher (Fig. 4a, c, g, k). In addition, on the test side of sample group 1 (Fig. 4a, c), Sr was detected up to approximately $120 \mu \mathrm{m}$ from the lesion front. Sr diffusion in dentin tended to be deeper for the sample groups demineralized for 2 and 3 weeks and remineralized thereafter (Fig. 4e, i). In these latter samples, the Ca content on the test side (Fig. 4e, i) was lower than or similar to that on the control side of the samples (Fig. 4f, j, respectively).

Figure $4 \mathrm{a}$, e, and $\mathrm{k}$ show that the Fuji IX restoration is composed of approximately $15 \% \mathrm{Sr}$ and $\mathrm{F}$. These figures also show the presence of $\mathrm{Ca}$ and $\mathrm{P}$ in the restoration migrating from the SDTF. The gap of a few micrometers, where no element concentration was detected, corresponds to the gap between the restoration and the dentin, as shown in Fig. 2a.

To quantify $\mathrm{Ca}, \mathrm{P}, \mathrm{F}$, and $\mathrm{Sr}$ uptake levels in remineralized dentin, the areas under the elemental concentration $v s$. depth curves were measured and compared for each element (for the test and control sides of samples), as described above in the Materials and Methods. As shown in Table 2, the aggregate content of $\mathrm{Ca}, \mathrm{P}, \mathrm{Sr}$, and $\mathrm{F}$ was greater on the test side than on the control side of samples, for all sample groups. Ca content accounted for $68 \%, 75 \%$, and $36 \%$ of the aggregated mineral uptake content (absolute difference) for sample groups 1, 2, and 3 , respectively. The absolute difference between the test and control sides of samples shows that aggregate mineral uptake after remineralization decreased as demineralization time increased. This is particularly evident at a demineralization time of 2 weeks. $\mathrm{Ca}, \mathrm{P}$, and $\mathrm{Sr}$ contents on the test sides of samples were significantly greater than those on the control sides $(P=0.01,0.01$, and 0.02 , respectively). However, F levels did not differ between the test and control sides of samples $(P=0.2)$.

\section{Determination of mechanical properties}

Figure 5 shows the hardness and Young's modulus profiles for the three groups of samples. As shown in Fig. 5a and $\mathrm{b}$, the values for $\mathrm{H}$ and $\mathrm{E}$ on the control side of samples were similar to a depth of $130 \mu \mathrm{m}$ from the lesion front, regardless of demineralization time. However, increasing demineralization time degraded the mechanical properties, i.e., $\mathrm{H}$ and $\mathrm{E}$, of dentin at depths greater than 130 $\mu \mathrm{m}$. In sample group 1 , the values for $\mathrm{H}$ and $\mathrm{E}$ at 300 $\mu \mathrm{m}$ from the lesion front were $0.92 \pm 0.15$ and $23.63 \pm$ $2.42 \mathrm{GPa}$, respectively. Greater demineralization time (samples groups 2 and 3) was associated with a gradual decrease in the mechanical properties in deep dentin. For example, at a depth of $300 \mu \mathrm{m}$ from the lesion front, the hardness values for sample groups 2 and 3 were 35\% and $50 \%$ lower than that of sample group 1. Similarly, at the same depth, the Young's modulus values for sample groups 2 and 3 were $23 \%$ and $38 \%$ lower than that of sample group 1.

As shown in Fig. $5 \mathrm{c}$ and $\mathrm{d}, \mathrm{H}$ and $\mathrm{E}$ values on the test side were greater than those on the control side of 

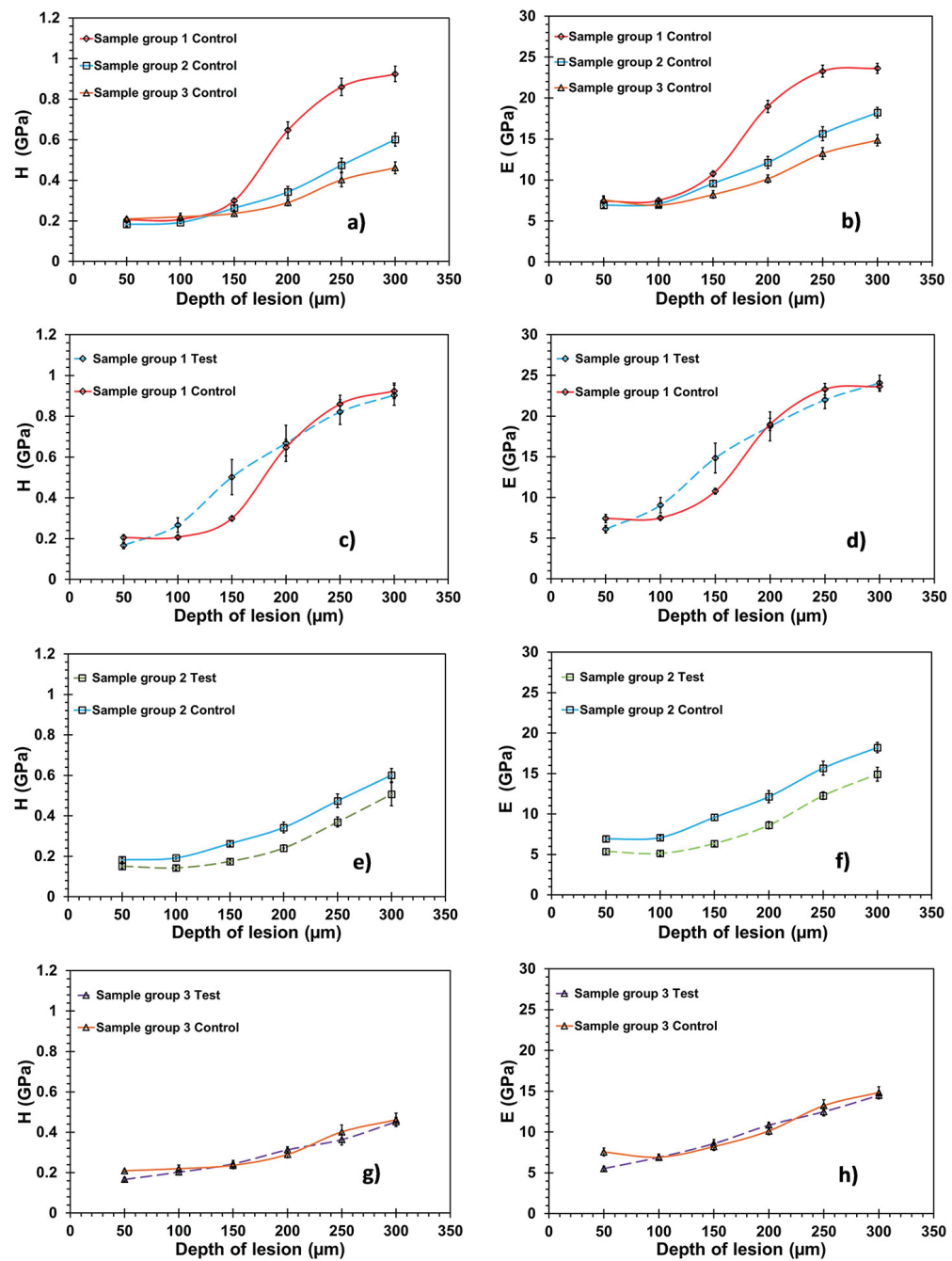

Fig. 5 Hardness and Young's modulus, with standard error bars, measured at a maximum load of $50 \mathrm{mN}$ across the dentin for $\mathrm{a}, \mathrm{b}$ ) the control sides of the three sample groups and the test and control sides of c,d) sample group 1, e,f) sample group 2, and g, h) sample group 3. Each point is the average of 16 measurements of four different samples from the same group.

Table 2 Area under the curve (elemental concentration vs. depth, Fig. 4) values for Ca and aggregate Ca, P, F, and $\mathrm{Sr}$ on the test and control sides of samples

\begin{tabular}{|c|c|c|c|c|c|c|}
\hline \multirow{2}{*}{ Sample group } & \multicolumn{3}{|c|}{ Ca level } & \multicolumn{3}{|c|}{ Aggregate $\mathrm{Ca}, \mathrm{P}, \mathrm{F}$, and $\mathrm{Sr}$ level } \\
\hline & Test side (SD) & Control side (SD) & Absolute difference (SD) & Test side (SD) & Control side (SD) & Absolute difference (SD) \\
\hline 1 & $9295(126)$ & $7182(665)$ & $2113(540)$ & $14705(262)$ & $11596(946)$ & $3109(683)$ \\
\hline 2 & 9319 (933) & $7007(261)$ & $2312(672)$ & $14469(842)$ & $11386(335)$ & $3082(507)$ \\
\hline 3 & 7013 (908) & 6648 (472) & $365(436)$ & $11746(1239)$ & $10719(904)$ & $1027(335)$ \\
\hline
\end{tabular}

$\mathrm{SD}$, standard deviation. Calculation of the absolute difference between the test and control sides enabled comparison of mineral uptake between sample groups.

samples at depths of 50 to $200 \mu \mathrm{m}$ from the lesion front in sample group 1. However, the test side of samples from groups 2 and 3 showed no improvement of mechanical properties (Fig. 5 c-h) after remineralization.

\section{Discussion}

Demineralization for different time periods degraded the mechanical properties of deep dentin (Fig. 5a, b).
After 1 week of demineralization, $\mathrm{H}$ and $\mathrm{E}$ were affected within the first $300 \mu \mathrm{m}$ from the lesion front. At a depth of $300 \mu \mathrm{m}, \mathrm{H}$ and $\mathrm{E}$ values were consistent with previously reported values for human molar dentin $(19,22,23)$. At 2 weeks of demineralization and later, however, the mechanical properties further decreased in deep dentin, indicating substantial degradation of deep dentin with longer demineralization. 


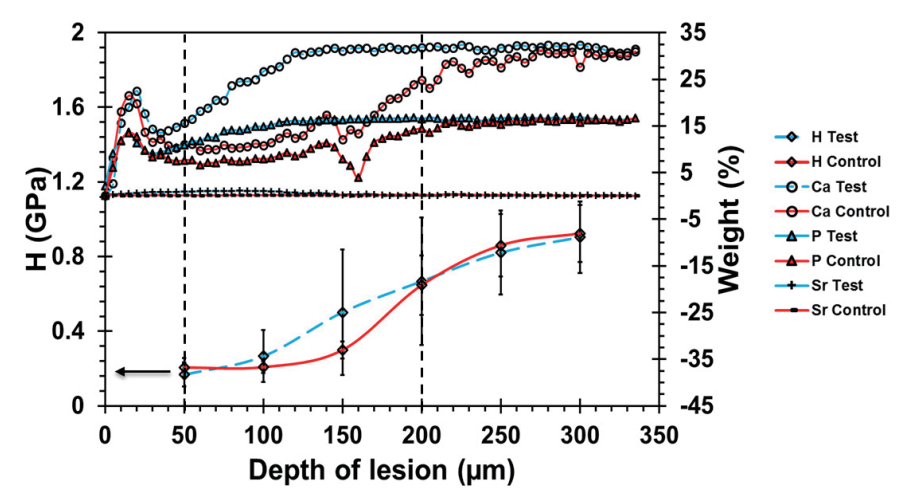

Fig. 6 Hardness values and $\mathrm{Ca}, \mathrm{P}$, and $\mathrm{Sr}$ levels in sample group 1.

We used an in vitro experimental design to simulate in vivo remineralization of demineralized dentin under Fuji IX restorations. The results clearly demonstrate ionic exchange between GIC and SDTF. Indeed, Sr (from Fuji IX) and greater amounts of $\mathrm{Ca}$ and $\mathrm{P}$ (from the SDTF) were seen on the test side of the samples (Fig. 4, Table 2). Sr was found up to $120 \mu \mathrm{m}$ from the lesion front of remineralized samples after 1 week of demineralization and tended to diffuse more deeply in dentin of remineralized samples with increasing duration of demineralization. The greater depth of mineral loss with increasing duration of demineralization leaves space for Sr to diffuse more deeply in demineralized dentin during remineralization. In these specimens, $\mathrm{Ca}$ content was lower on the test side than on the control side. Sr can replace $\mathrm{Ca}$ without disrupting hydroxyapatite structure, as it has a similar ionic radius and valence to $\mathrm{Ca}\left(\mathrm{Sr}^{2+}\right.$ $=0.113 \mathrm{~nm}, \mathrm{Ca}^{2+}=0.099 \mathrm{~nm}$ ) (Curzon EJ, Cutress TW. Trace elements and dental disease, John Wright, 1983). Close to the lesion front, where the dentin was highly demineralized, there was space to accommodate both $\mathrm{Ca}$ and $\mathrm{Sr}$ (Fig. 4a, c), but there was competition between $\mathrm{Sr}$ and $\mathrm{Ca}$ uptake deeper in dentin, because of the greater atomic weight of Sr. Thus, the relative weight of $\mathrm{Ca}$ decreased with $\mathrm{Sr}$ uptake (Fig. 4e, i). This phenomenon was previously reported in a bone study (24).

The uptake of mineral elements in sample group 1 (6 weeks of remineralization after 1 week of demineralization) increased the mechanical properties, $\mathrm{H}$ and $\mathrm{E}$, of the dentin at a depth of 50 to $200 \mu \mathrm{m}$ from the lesion front (Fig. 5c, d). As mentioned above, at these depths samples exhibited greater mineral element content on the test side than on the control side. Figure 6 illustrates $\mathrm{Ca}$, $\mathrm{P}$, and $\mathrm{Sr}$ content and $\mathrm{H}$ values for the test and control sides of sample group 1. The higher mineral content in the depth profile for the test side clearly matched the greater values of $\mathrm{H}$ (and E) (Fig. 5d) measured for sample group 1. However, the mechanical properties were not improved at a depth of $50 \mu \mathrm{m}$, despite the higher mineral concentrations on the test side of the samples. At this depth, the similar values for $\mathrm{H}$ (and E) - regardless of demineralization time - and for the test and control sides, showed that the dentin was substantially softened and that the minimum values for these properties might have been reached. The structural damage was presumably too severe because of the proximity to the lesion front (7), and the minerals gained on the test side might not have been functionally coupled to the organic dentin matrix (10).

Increasing the duration of demineralization to 2 weeks (sample group 2) extended structural damage (Fig. 5a, b) and loss of minerals in deep dentin (Fig. 4b, h, 1). Despite considerable uptake of minerals, the mechanical properties did not recover. The same trend was observed in sample group 3, in which mineral uptake was lower (Table 2).

It should be noted that we measured mechanical properties on dry dentin samples. Although measurement of these properties on fully hydrated dentin could yield lower $\mathrm{H}$ and $\mathrm{E}$ values $(10,20)$, the trends would likely be the same (10). Another point to note is that no protein was included in the composition of SDTF, as protein can alter ionic movement of $\mathrm{Ca}, \mathrm{P}, \mathrm{F}$, and $\mathrm{Sr}$ (14). However, an objective of this study was to investigate the role of specific electrolytes, such as $\mathrm{Ca}$ and $\mathrm{P}$, on remineralization of remnant demineralized dentin. The composition of SDTF was therefore designed to yield representative concentrations of $\mathrm{Ca}$ and $\mathrm{PO}_{4}$ ions in real dentinal tubular fluid.

In conclusion, this study showed a positive effect on restorations in terms of mineral uptake $(\mathrm{Ca}, \mathrm{P}$, and $\mathrm{Sr})$ in dentin demineralized for up to 3 weeks. However, restoration of mineral content and improvement of the mechanical properties $\mathrm{H}$ and $\mathrm{E}$ were only possible for dentin demineralized for 1 week under the present conditions. 


\section{Acknowledgments}

The authors would like to thank the Colgate Australian Clinical Dental Research Centre for their support and the GC Corporation for providing materials. The authors are grateful for use of the facilities and the scientific and technical assistance of the Australian Microscopy and Microanalysis Research Facility at the University of Adelaide.

\section{Conflict of interest}

The authors have no conflicts of interest to declare.

\section{References}

1. Featherstone JD (1999) Prevention and reversal of dental caries: role of low level fluoride. Community Dent Oral Epidemiol 27, 31-40.

2. Kidd EA (2004) How 'clean' must a cavity be before restoration? Caries Res 38, 305-313.

3. Kidd EA, Fejerskov O (2004) What constitutes dental caries? Histopathology of carious enamel and dentin related to the action of cariogenic biofilms. J Dent Res 83, C35-38.

4. Bertassoni LE, Habelitz S, Marshall SJ, Marshall GW (2011) Mechanical recovery of dentin following remineralization in vitro--an indentation study. J Biomech 44, 176-181.

5. Angker L, Nockolds C, Swain MV, Kilpatrick N (2004) Correlating the mechanical properties to the mineral content of carious dentine--a comparative study using an ultra-micro indentation system (UMIS) and SEM-BSE signals. Arch Oral Biol 49, 369-378.

6. Featherstone JDB (2004) The continuum of dental caries-evidence for a dynamic disease process. J Dent Res 83, C39-42.

7. Ngo HC, Mount G, Mc Intyre J, Tuisuva J, Von Doussa RJ (2006) Chemical exchange between glass-ionomer restorations and residual carious dentine in permanent molars: an in vivo study. J Dent 34, 608-613.

8. Yamamoto K, Arai K, Fukazama K, Fukui K, Nagamatsu K, Kato $\mathrm{K}$ et al. (2005) Effect of plaque fluoride released from a glass-ionomer cement on enamel remineralization in situ. Caries Res 39, 157-160.

9. Takahashi Y, Imazato S, Kaneshiro AV, Ebisu S, Frencken JE, Tay FR (2006) Antibacterial effects and physical properties of glass-ionomer cements containing chlorhexidine for the ART approach. Dent Mater 22, 647-652.

10. Bertassoni LE, Habelitz S, Kinney JH, Marshall SJ, Marshall GW Jr (2009) Biomechanical perspective on the remineralization of dentin. Caries Res 43, 70-77.
11. Bassed RB, Briggs C, Drummer OH (2011) Age estimation and the developing third molar tooth: an analysis of an Australian population using computed tomography. J Forensic Sci $56,1185-1191$

12. Jung YH, Cho BH (2014) Radiographic evaluation of third molar development in 6- to 24-year-olds. Imaging Sci Dent 44, 185-191.

13. Mjor IA (2009) Dentin permeability: the basis for understanding pulp reactions and adhesive technology. Braz Dent $\mathrm{J}$ 20, 3-16.

14. Ozok AR, Wu MK, Ten Cate JM, Wesselink PR (2004) Effect of dentinal fluid composition on dentin demineralization in vitro. J Dent Res 83, 849-853.

15. Coffey CT, Ingram MJ, Bjorndal AM (1970) Analysis of human dentinal fluid. Oral Surg Oral Med Oral Pathol Oral Radiol 30, 835-837.

16. Shellis RP (1994) Effects of a supersaturated pulpal fluid on the formation of caries-like lesions on the roots of human teeth. Caries Res 28, 14-20.

17. Oliver WC, Pharr GM (1992) An improved technique for determining hardness and elastic modulus using load and displacement sensing indentation experiments. J Mater Res 7, 1564-1583.

18. O’Brien S, Keown AJ, Constantino P, Xie Z, Bush MB (2014) Revealing the structural and mechanical characteristics of ovine teeth. J Mech Behav Biomed Mater 30, 176-185.

19. Mahoney E, Holt A, Swain M, Kilpatrick N (2000) The hardness and modulus of elasticity of primary molar teeth: an ultra-micro-indentation study. J Dent 28, 589-594.

20. Bertassoni LE, Swain MV (2012) Influence of hydration on nanoindentation induced energy expenditure of dentin. J Biomech 45, 1679-1683.

21. Loch C, Swain MV, van Vuuren LJ, Kieser JA, Fordyce RE (2013) Mechanical properties of dental tissues in dolphins (Cetacea: Delphinoidea and Inioidea). Arch Oral Biol 58, 773-779.

22. Zhang YR, Du W, Zhou XD, Yu HY (2014) Review of research on the mechanical properties of the human tooth. Int J Oral Sci 6, 61-69.

23. Miyazaki M, Inage H, Onose H (2002) Use of an ultrasonic device for the determination of elastic modulus of dentin. $\mathrm{J}$ Oral Sci 44, 19-26.

24. Li C, Paris O, Siegel S, Roschger P, Paschalis EP, Klaushofer $\mathrm{K}$ et al. (2010) Strontium is incorporated into mineral crystals only in newly formed bone during strontium ranelate treatment. J Bone Miner Res 25, 968-975. 